\title{
Indentation fatigue in silicon nitride, alumina and silicon carbide ceramics
}

\author{
A K MUKHOPADHYAY \\ Central Glass and Ceramic Research Institute, Kolkata 700 032, India
}

\begin{abstract}
Repeated indentation fatigue (RIF) experiments conducted on the same spot of different structural ceramics viz. a hot pressed silicon nitride (HPSN), sintered alumina of two different grain sizes viz. $1 \mu \mathrm{m}$ and $25 \mu \mathrm{m}$, and a sintered silicon carbide (SSiC) are reported. The RIF experiments were conducted using a Vicker's microhardness tester at various loads in the range 1-20 N. Subsequently, the gradual evolution of the damage was characterized using an optical microscope in conjunction with the image analysing technique. The materials were classified in the order of the decreasing resistance against repeated indentation fatigue at the highest applied load of $20 \mathrm{~N}$. It was further shown that there was a strong influence of grain size on the development of resistance against repeated indentation fatigue on the same spot. Finally, the poor performance of the sintered silicon carbide was found out to be linked to its previous thermal history.
\end{abstract}

Keywords. Indentation fatigue; silicon nitride; silicon carbide; grain size.

\section{Introduction}

Short length, microstructural scale cracks are often present on the surface of structural ceramics caused by the processing related defects or as edge flaws during the machining and surface finishing operations. Such precursor cracks can initiate significant damage on subsequent stress application. Particularly, during repeated contact events such small cracks can grow by a fatigue induced slow crack growth process which may finally lead to a premature brittle failure. One of the ways to simulate the fatigue induced growth of short, microstructural scale cracks which occur during repeated contact events in structural ceramics, is the study of repeated indentation fatigue (RIF) (Lawn et al 1981). Investigations on $\mathrm{Al}_{2} \mathrm{O}_{3}$ (Vaughan et al 1987; Reece and Guiu 1990, 1991), ZTA (Vaughan and Guiu 1987), Mg-PSZ (Pajares et al 1995), SiC-YAG, $\mathrm{Al}_{2} \mathrm{O}_{3}-\mathrm{CaO} \cdot 6 \mathrm{Al}_{2} \mathrm{O}_{3}$, mica-glass composites (Padture and Lawn 1995), $\mathrm{Y}-\mathrm{TZP}-\mathrm{Al}_{2} \mathrm{O}_{3}$ layered composite (Wang and $\mathrm{Hu}$ 1996) and $\mathrm{Na}_{2} \mathrm{O}-\mathrm{CaO}-\mathrm{SiO}_{2}$ glass (Spasks and Hutchings 1992; Banerjee and Sarkar 1995) as well as single crystal $\mathrm{CaF}_{2}$ (Maerky et al 1997) have been reported. The applied loads were either critical (9.83000 N) (Vaughan and Guiu 1987; Vaughan et al 1987; Reece and Guiu 1990, 1991; Spasks and Hutchings 1992; Padture and Lawn 1995; Pajares et al 1995; Maerky et al 1997) or subcritical (0.1-1 N) (Banerjee and Sarkar 1995) and the RIF experiments carried out with (Vaughan and Guiu 1987; Vaughan et al 1987; Reece and Guiu 1990, 1991) or without (Spasks and Hutchings 1992; Banerjee and Sarkar 1995; Padture and Lawn 1995; Pajares et al 1995) application of preloads have been reported. In most cases a sharp Vicker's diamond indenter
(Vaughan and Guiu 1987; Vaughan et al 1987; Reece and Guiu 1990, 1991; Spasks and Hutchings 1992; Banerjee and Sarkar 1995) and occasionally, a blunt indenter (Spasks and Hutchings 1992; Padture and Lawn 1995; Pajares et al 1995) have been used. The most accepted mechanism of the RIF is the nucleation, formation and fatigue growth of cone/lateral cracks (depending on indenter shape: blunt/sharp) which intersect the surface to affect the material removal by a chip detachment (Vaughan and Guiu 1987; Vaughan et al 1987; Reece and Guiu 1990, 1991; Spasks and Hutchings 1992). The purpose of the present RIF study was to investigate: (i) the comparative performance of $\mathrm{Si}_{3} \mathrm{~N}_{4}$ (HPSN), alumina $\left(\mathrm{Al}_{2} \mathrm{O}_{3}\right)$ and a thermal shock damaged $\mathrm{SiC}$ and (ii) the influence of alumina grain size $(1$ and $25 \mu \mathrm{m})$ under RIF loadings.

\section{Experimental}

Fully dense hot-pressed $\mathrm{Si}_{3} \mathrm{~N}_{4}$ (HPSN) and 96\% of theoretical density sintered $\mathrm{SiC}(\mathrm{SSiC})$ samples were commercially obtained. $99.9 \%$ pure alumina powder (TM-DR, $d_{50}=0.23 \mu \mathrm{m}$, Taimai Bros. Inc., Tokyo, Japan) was conventionally sintered $\left(1310-1700^{\circ} \mathrm{C}\right)$ in air to $>98 \%$ of the theoretical density (Mukhopadhyay and Mai 1993; Mukhopadhyay et al 1997). Thermal shock damage (TSD) was deliberately introduced in SSiC by single quenching from $1500^{\circ} \mathrm{C}$ into a silicone oil bath kept at $30^{\circ} \mathrm{C}$ in air (Chakraborty et al 1985). Both the hardness and fracture toughness $\left(K_{\mathrm{IC}}\right)$ by the indentation technique were determined for the polished HPSN, alumina samples $(\mathrm{CLA} \approx 0.34-0.52 \mu \mathrm{m})$, and thermal shock damaged SSiC 
samples, at a load of $20 \mathrm{~N}$ using a Vicker's pyramidal diamond indenter in air in a microhardness tester (Shimadzu, HMV 2000, Japan) (Mukhopadhyay et al 1990). The RIF experiments were conducted with the same Vicker's indenter in air under ambient laboratory conditions at an intermediate load range $(1-20 \mathrm{~N})$. The pre-loading of samples was avoided. The duration of each contact cycle was $30 \mathrm{~s}$. The interval between any two successive contact cycles on the same spot was also $30 \mathrm{~s}$. The evolution of RIF damage was characterized by a reflected light optical
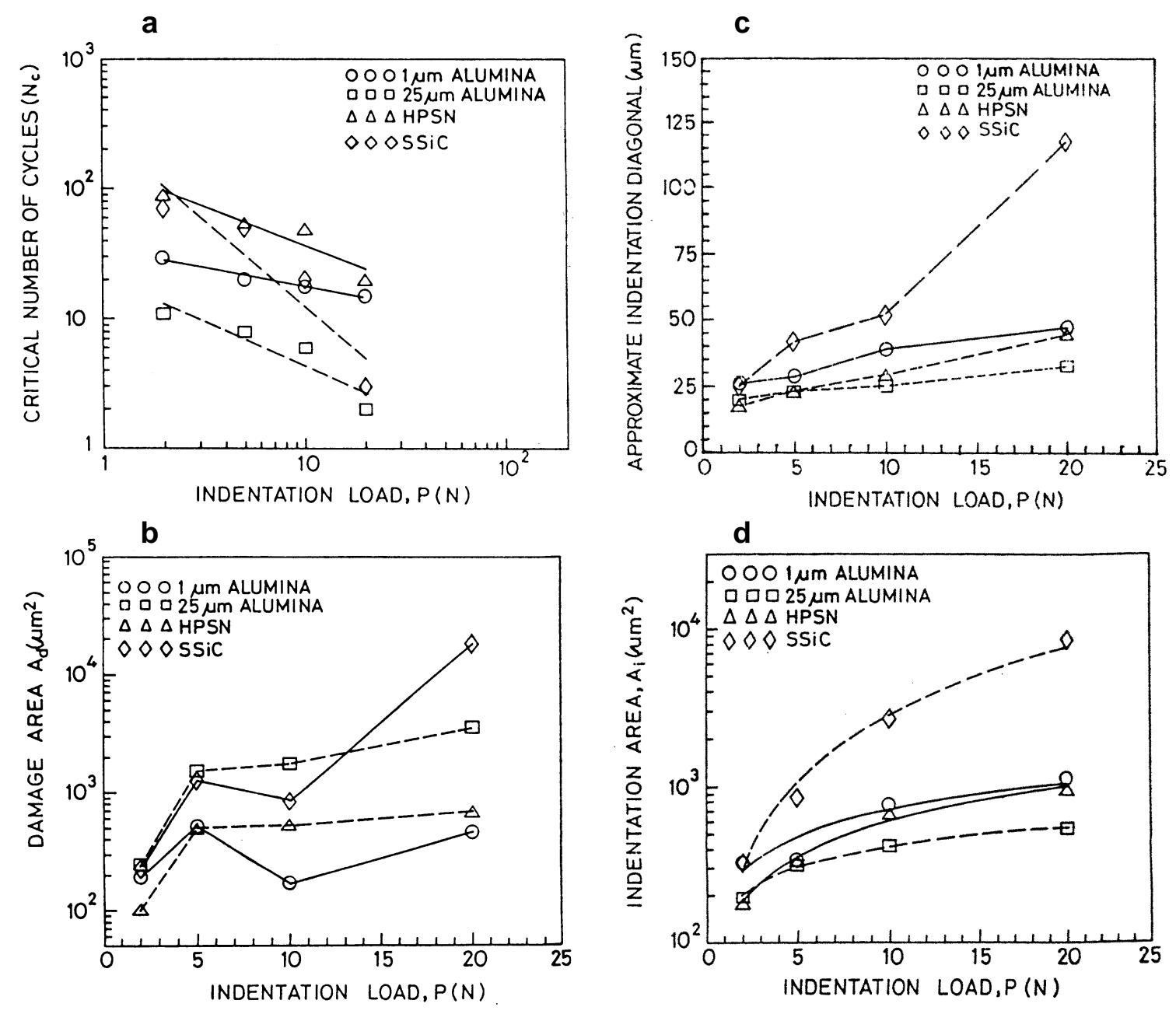

e

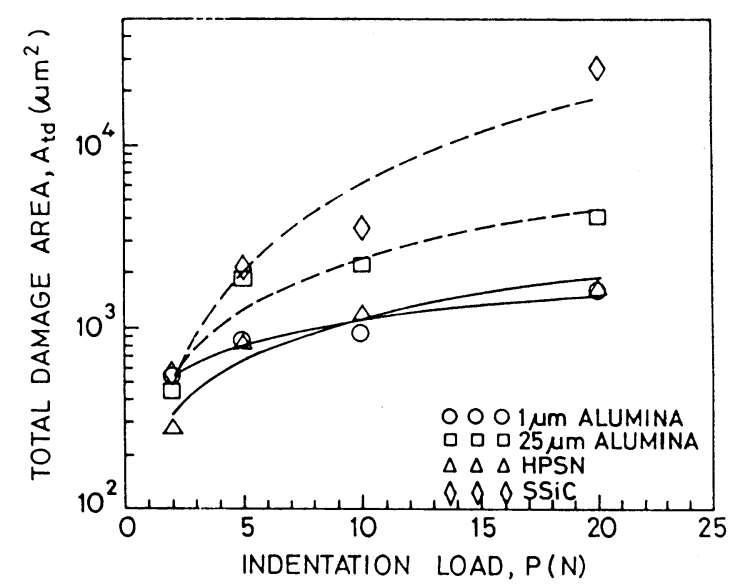

Figure 1. a. Critical number of cycles $\left(N_{\mathrm{c}}\right)$ vs indentation load $(P)$ of HPSN, SSiC and alumina, b. damage area vs indentation load $(P)$ of HPSN, SSiC and alumina, c. indentation diagonal vs indentation load $(P)$ of HPSN, SSiC and alumina, d. indentation area vs indentation load $(P)$ of HPSN, SSiC and alumina and e. total damage area vs indentation load $(P)$ of HPSN, SSiC and alumina. 
microscope using an image analyser (Leica, Q500 MC, $\mathrm{UK}$, resolution: better than $\pm 2 \mu \mathrm{m}$ ) to obtain a quantitative data on the indentation area $\left(A_{\mathrm{i}}\right)$, the damage area surrounding the indentation $\left(A_{\mathrm{d}}\right)$ and the total damage area, $A_{\mathrm{td}}\left(\approx A_{\mathrm{i}}+A_{\mathrm{d}}\right)$. The number of cycles required to cause chipping was taken as the critical number of cycles $\left(N_{\mathrm{c}}\right)$ for a given combination of load $(P)$ and material. All reported data is an average of at least 3-5 experiments. Typical, overall average scatter in the data was less than $10 \%$.

\section{Results}

The data on the various RIF related parameters e.g. the critical number of cycles to failure $\left(N_{\mathrm{c}}\right)$, total damage area $\left(A_{\mathrm{td}}\right)$, only damage area $\left(A_{\mathrm{d}}\right)$, approximate indentation diagonal $\left(d_{\mathrm{i}}\right)$ and indentation area $\left(A_{\mathrm{i}}\right)$ as functions of the repeated indentation load $(P)$ applied on HPSN, SSiC and $\mathrm{Al}_{2} \mathrm{O}_{3}$ (grain sizes, G-1 and $25 \mu \mathrm{m}$ ) ceramics are shown in figures $1 \mathrm{a}-\mathrm{d}$. The concept of the total damage area evolving as a sum total of the indentation area and the only damage area surrounding the distorted indentation is explained in figure 2. The data on the grain sizes, hardness and fracture toughness of the present ceramics investigated, are given in table 1.

For all the materials, the critical number of cycles $\left(N_{\mathrm{c}}\right)$ bear an empirical inverse power law relationship with the load $(P)$ (figure 1a), as also observed by others (Vaughan and Guiu 1987; Vaughan et al 1987; Reece and Guiu 1990, 1991; Padture and Lawn 1995; Pajares et al 1995). However, the total damage area $\left(A_{\mathrm{td}}\right)$ increased with the load $(P)$ following an empirical power law relationship (figure 1b). Amongst the present materials studied, HPSN showed the highest indentation fatigue resistance. Further,

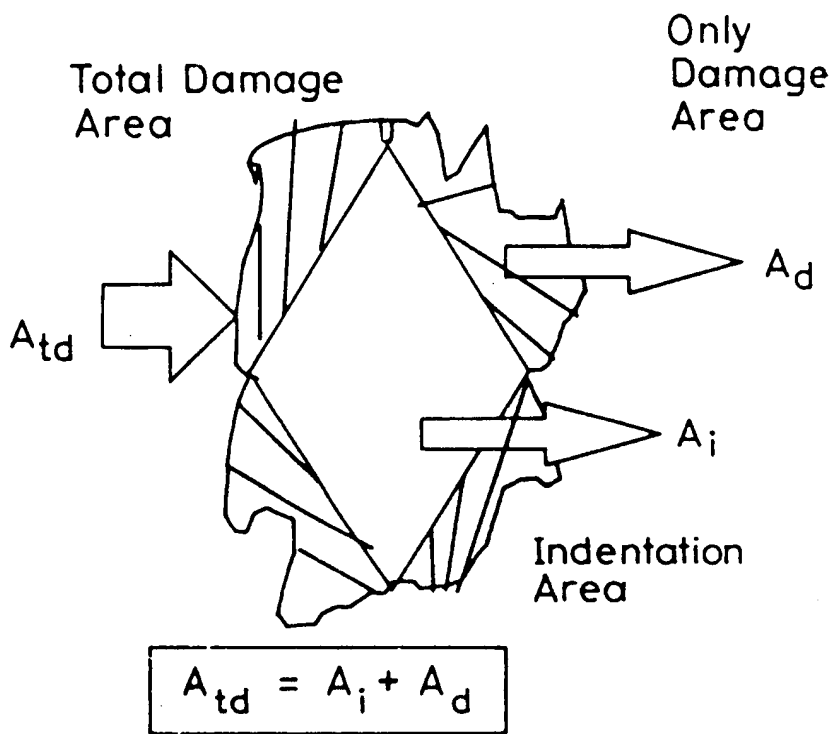

Figure 2. Relation between $A_{\mathrm{i}}, A_{\mathrm{d}}$ and $A_{\mathrm{td}}$ of HPSN, SSiC and alumina. at any given load the number of cycles to failure was higher for the $1 \mu \mathrm{m}$ grain sized alumina than for the $25 \mu \mathrm{m}$ grain sized. This presence of a grain size effect in the RIF behaviour of the alumina is similar to what have been found in abrasive wear mechanisms of the same (Mukhopadhyay and Mai 1993; Mukhopadhyay et al 1997).

In order of the increasing magnitude of the total damage area $\left(A_{\mathrm{td}}\right)$ at $P=3 \mathrm{~N}$ for the ceramics the sequence was HPSN, $25 \mu \mathrm{m}$ followed by $1 \mu \mathrm{m}$ alumina and SSiC. However, the sequence changed to HPSN, $1 \mu \mathrm{m}$ and $25 \mu \mathrm{m}$ alumina and $\mathrm{SSiC}$ at $P=20 \mathrm{~N}$ (figure 1b). This observation is also supported by the optical micrographs of RIF in HPSN (figure 3) as compared to those of other materials (figures 4-6). The effect of RIF was not that severe on the thermal shock damaged $\mathrm{SSiC}$ at low load $(P=3 \mathrm{~N})$. However, at the highest applied load of $20 \mathrm{~N}$, the stress field develops to a considerable magnitude so as to cause a huge chip out of the material due to a mechanical spalling action (figure 4). This could have been caused by (a) the presence of a large surface flaw density introduced by the intentional thermal shock and (b) a very rapid post

Table 1. Properties of the structural ceramics investigated.

\begin{tabular}{lccc}
\hline Sample & $\begin{array}{c}\text { Grain size } \\
(\mu \mathrm{m})\end{array}$ & $\begin{array}{c}\text { Hardness, } H \\
(\mathrm{GPa})\end{array}$ & $\begin{array}{c}\text { Fracture toughness, } K_{\mathrm{IC}} \\
\left(\mathrm{MPa} \mathrm{m}^{1 / 2}\right)\end{array}$ \\
\hline HPSN & $3 \cdot 2$ & $20 \cdot 6$ & $4 \cdot 7$ \\
SSiC & $4 \cdot 1$ & $31 \cdot 3$ & $3 \cdot 0$ \\
Alumina & $1 \cdot 0$ & $17 \cdot 9$ & $3 \cdot 6$ \\
Alumina & 25 & $13 \cdot 7$ & $4 \cdot 4$ \\
\hline
\end{tabular}

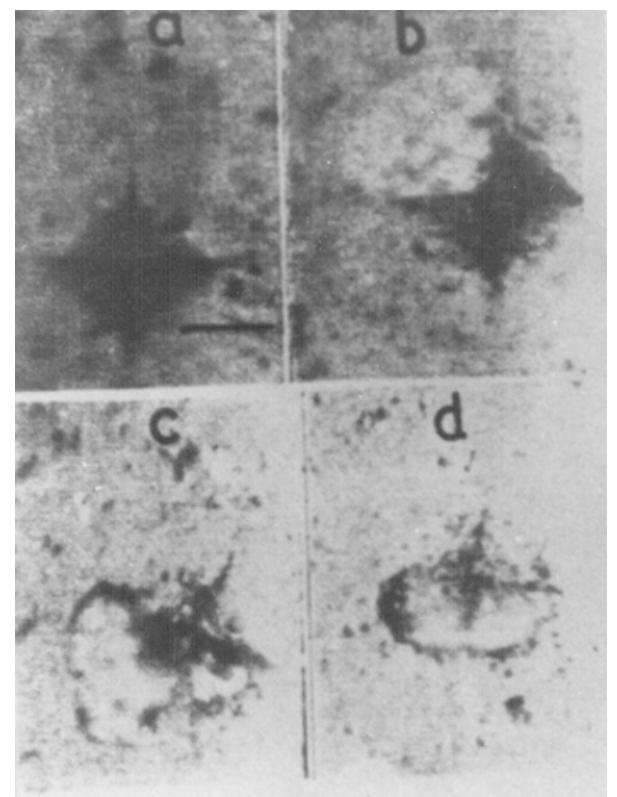

Figure 3. RIF behaviour of HPSN at various loads a. $20 \mathrm{~N}$, b. $10 \mathrm{~N}$, c. $5 \mathrm{~N}$ and d. $3 \mathrm{~N}($ scale $=20 \mu \mathrm{m})$. 
indentation growth of the subsurface lateral cracks due to RIF which occurred within only a few contact cycles of the sharp indenter at such high load.

The only damage area $\left(A_{\mathrm{d}}\right)$, approximate value of the indentation diagonal (di) and hence, the indentation area $\left(A_{\mathrm{i}}\right)$-all parameters increased with the increase in repeated indentation load applied on these ceramics (figure 1c-e). The ultimate deciding parameter was thus found out to be the total damage area. This parameter conceptually scales with actual extent of the physical fatigue damage in a given combination of load and a brittle ceramic under a given environmental condition. The concept of interconnection between $A_{\mathrm{td}}, A_{\mathrm{d}}$ and $A_{\mathrm{i}}$ being proposed in the present work, is explained in figure 2 .

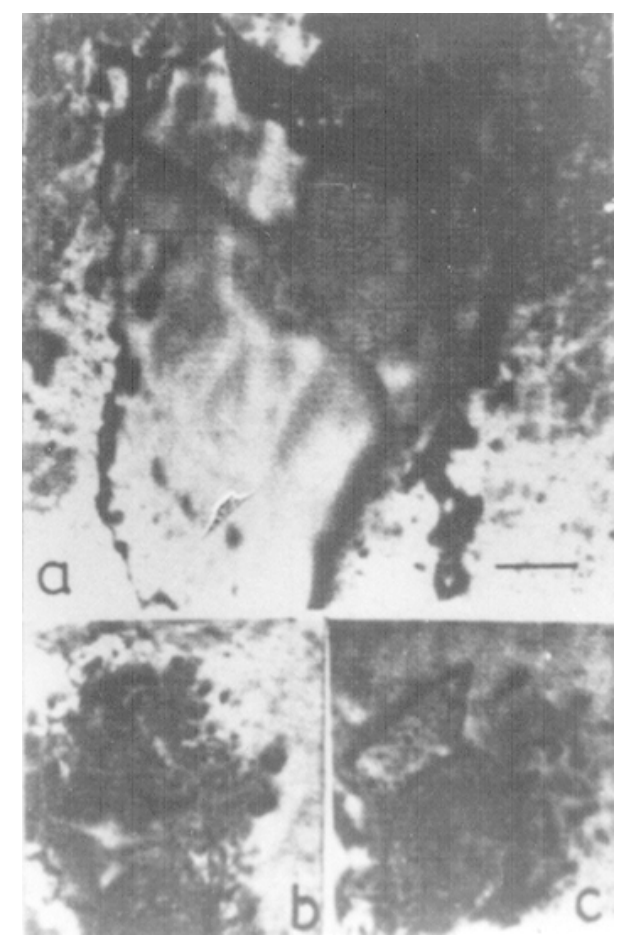

Figure 4. RIF behaviour of $\mathrm{SSiC}$ at various loads a. $20 \mathrm{~N}$, b. $10 \mathrm{~N}$ and c. $5 \mathrm{~N}($ scale $=20 \mu \mathrm{m})$.

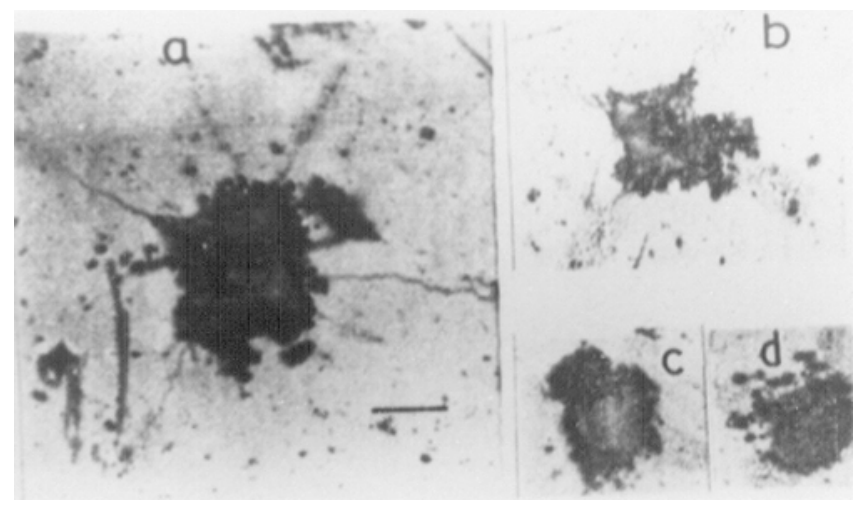

Figure 5. RIF behaviour of alumina at various loads a. $20 \mathrm{~N}$, b. $10 \mathrm{~N}$, c. $5 \mathrm{~N}$ and d. $3 \mathrm{~N}$; $(\mathrm{G}=1 \mu \mathrm{m})($ scale $=20 \mu \mathrm{m})$.
The RIF resistance of $1 \mu \mathrm{m}$ grain sized alumina was much superior to that of the $25 \mu \mathrm{m}$ grain sized alumina (figures $1 a-b, 5,6)$. This result can be rationalized in terms of (a) the presence of larger amount of residual stress in the 25 micron alumina compared to that of 1 micron alumina (Mukhopadhyay and Mai 1993), (b) the higher stress requirement to initiate grain boundary microcracking (table 1), in the 1 micron than that required in the 25 micron alumina (Mukhopadhyay et al 1997), and (c) the observation that fine grain sized alumina is more resistant than the coarse grain sized alumina, against mechanical fatigue (Reece and Guiu 1991).

Based on the data of the present work (figures 1-6) and those of the previous workers (Vaughan and Guiu 1987; Vaughan et al 1987; Reece and Guiu 1990, 1991; Spasks and Hutchings 1992; Padture and Lawn 1995; Pajares et al 1995; Wang and $\mathrm{Hu}$ 1996), the following simplified picture of the RIF mechanism can be proposed for brittle ceramics. Initially, both lateral and median crack systems were produced in a single indentation at loads greater than the critical load reaching a final equilibrium size on unloading the indenter. This is apparently due to the presence of a residual stress. The residual stress originates as a result of the mismatch traction between the plastically deformed zone just beneath the indenter and the surrounding area, pushed out over the elastic matrix. Repeated indentation on the same spot by the cyclic loading and unloading, simulates a slow, yet a fatigue growth process for both radial and lateral crack systems independent of the indenter shape. Because of the presence of a high

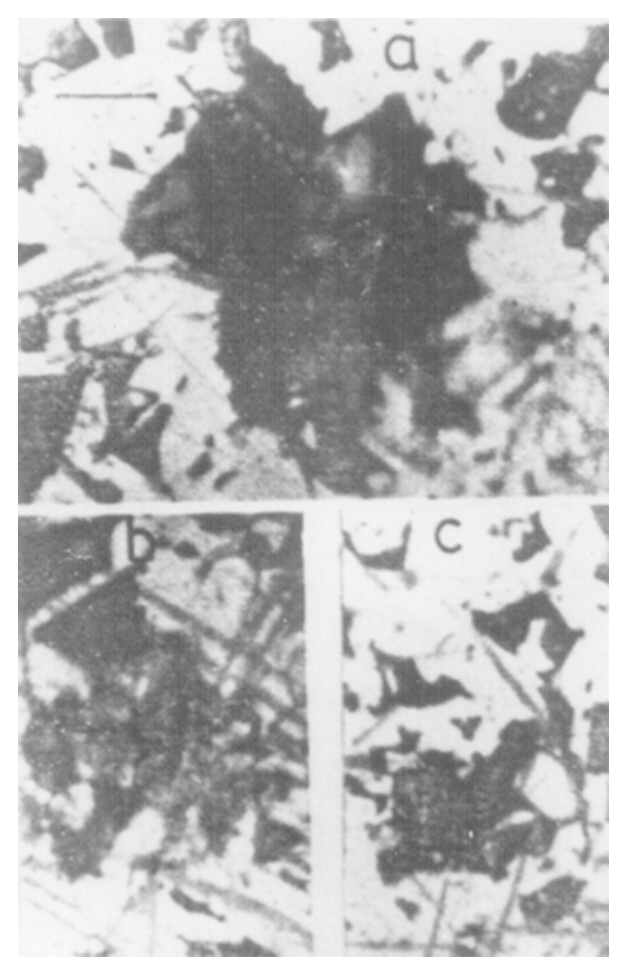

Figure 6. RIF behaviour of alumina at various loads a. $20 \mathrm{~N}$, b. $10 \mathrm{~N}$ and c. $5 \mathrm{~N} ;(\mathrm{G}=25 \mu \mathrm{m})($ scale $=20 \mu \mathrm{m})$. 
degree of residual strain in and around the damage zone, the process of fatigue growth can occur at a much lower load i.e. at applied stress intensities much lower than that required to cause failure in a single loading cycle. The residual strain originates from the repeated loading and unloading on the same spot in quick succession which prevents complete relaxation of the residual stress although, a part of it may be relieved through the damage evolution process (Vaughan and Guiu 1987; Vaughan et al 1987; Reece and Guiu 1990, 1991; Spasks and Hutchings 1992; Banerjee and Sarkar 1995; Padture and Lawn 1995; Pajares et al 1995; Wang and $\mathrm{Hu}$ 1996). Thus, on increasing the number of loading cycles the amount of total accumulated residual strain was also enhanced locally. So, the total damage area can be assumed to be indicative of the total amount of residual strain accumulated in the ceramic system. Finally, the lateral crack system intersects on the growth of the radial crack system on the free surface, chipping out the enclosed region providing evidence of a pure RIF behaviour. However, the details of such a process shall depend on the surface condition, grain size, mechanical properties $\left(E / H, K_{\mathrm{IC}}\right)$ and the presence or absence of the additional residual stress retained from processing related factors.

\section{Conclusions}

The major conclusions of the present work are:

(I) Amongst the materials investigated HPSN is the most RIF resistant under the present experimental conditions $(1-20 \mathrm{~N})$.

(II) The intentional thermal shock damage (TSD) induced in $\mathrm{SSiC}$ shows that TSD can lead to a very poor per- formance by an otherwise well known structural ceramic under the conditions of RIF.

(III) $1 \mu \mathrm{m}$ grain sized alumina has a much higher RIF resistance than that of $25 \mu \mathrm{m}$ grain sized alumina.

\section{Acknowledgements}

The keen interest of Dr H S Maiti, Director, Central Glass and Ceramic Research Institute, Kolkata, in the present work and the experimental assistance of $\mathrm{Mr}$ A Talukdar and $\mathrm{Mr} \mathrm{A} \mathrm{K}$ Bhadra are deeply appreciated.

\section{References}

Banerjee R and Sarkar B K 1995 Glass Sci. Technol. 68177

Chakravorty D, Mukhopadhyay A K and Mukherjee J 1985 Rev. Int. Hautes Temp. 22105

Lawn B R, Marshall D B, Anstis G R and Dubbs T P 1981 J. Mater. Sci. 162846

Maerky C, Henshall J L, Hooper R M and Guillon M O 1997 J. Eur. Ceram. Soc. 1761

Mukhopadhyay A K and Mai Y-W 1993 Wear 162-164 258

Mukhopadhyay A K, Datta S K and Chakraborty D 1990 J. Eur. Ceram. Soc. 6303

Mukhopadhyay A K, Chakraborty D, Swain M V and Mai Y-W 1997 J. Eur. Ceram. Soc. 1791

Padture N P and Lawn B R 1995 Acta Metall. Mater. 431609

Pajares A, Wei L, Lawn B R and Marshall D B 1995 J. Mater. Res. 102613

Reece M and Guiu F 1990 J. Am. Ceram. Soc. 731004

Reece M and Guiu F 1991 J. Am. Ceram. Soc. 74148

Spasks A J and Hutchings I M 1992 J. Mater. Sci. Lett. 11918

Vaughan D A J and Guiu F 1987 Proc. Br. Ceram. Soc. 39101

Vaughan D A J, Guiu F and Dalmau M R 1987 J. Mater. Sci. Lett. 6689

Wang S and Hu X 1996 J. Am. Ceram. Soc. 79553 